The research presented in this paper was developed within the project "The Open Innovation Project (IOIT)" funded by the European Union INTERREG IVB NWE Programme (Funding code: 166F-IOIT).

www.openinnovationproject.eu
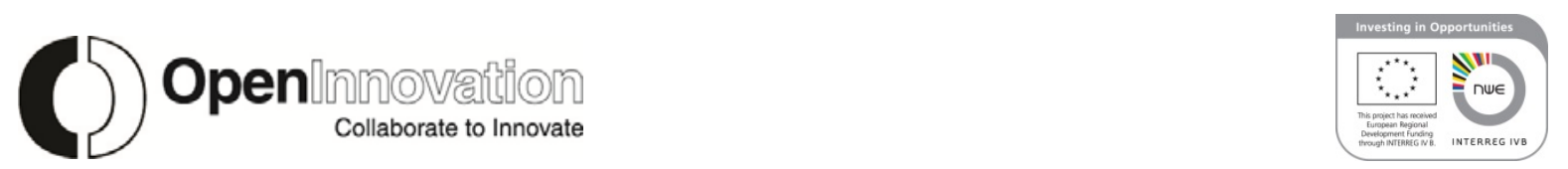

Please quote as: Ebel, P.; Zogaj, S.; Bretschneider, U. \& Leimeister, J. M. (2013): Look at Me - Using Signaling Theory to Design Profile Functionalities for Virtual Ideas Communities. In: R\&D Management Conference, Manchester, United Kingdom. 


\title{
Using Signaling Theory to Design Profile Functionalities for Virtual Ideas Communities
}

\author{
Philipp Ebel \\ Shkodran Zogaj \\ Ulrich Bretschneider \\ Jan Marco Leimeister \\ Information Systems \\ Kassel University \\ Pfannkuchstraße 1 \\ 34121 Kassel \\ [ph.ebel|zogaj|bretschneider|leimeister]@uni-kassel.de
}

\begin{abstract}
In existing virtual ideas communities (VICs) there are no functionalities that allow members to signal directly their skills and competences. While through submitted ideas, users of VICs can signal their competencies indirectly, a possibility to communicate explicitly their skills and competencies is missing. Drawing from existing literature within the field of VICs we assume that users that have the possibility to signal their skills will be more active. Hence, to satisfy members' self-marketing needs, community members have to be provided with possibilities or, more specifically, functionalities which enable them to signalize their proficiencies. Against this backdrop, we designed profile functionalities based on the signaling theory. In addition to systematically designing these IT artefacts, our research in progress also contains a first evaluation.
\end{abstract}

Keywords: virtual ideas communities, user profiles, signaling theory, design science 


\section{Introduction}

This paper describes the case of SAPiens, which is a virtual ideas community hosted by SAP, a German software provider. SAPiens enables customers, users and employees of SAP to develop, publish and evaluate ideas in a collaborative manner. These ideas basically concern new, respectively optimized functionalities regarding the SAP ERP software and services that are offered by SAP. Given these characteristics, SAPiens can be considered as a typical ideas community, within which like-minded people come together to work on a concrete task and to push a specific innovation project further (Gerybadze, 2004; von Hippel, 2005).

Virtual ideas communities (VIC) such as Dell's “Ideastorm” are becoming increasingly popular as platforms for firms to engage customers in their innovation activities. In general, VICs are kept very simple: customers can submit ideas and discuss these ideas in a collaborative manner. While these functionalities enable companies to improve their product and services in a co-productive manner, the potential of idea communities has not yet been completely utilized. This is because there is evidence that customers participate in VICs not only to satisfy their creative urge and product-related curiosity (fun-motive), but also for self-marketing reasons (Bretschneider, 2012). It is found that customers seek to demonstrate their capabilities and skills through their submitted ideas. The reason for doing so is the desire to promote own business opportunities by showing their skills to the community owner as well as to be recognized by peers and to enhance the reputation within the community (Hars \& Ou, 2002a; Hertel et al., 2003a; Lakhani \& Wolf, 2005; Shah, 2006). Hence, in order to be able to satisfy the depicted motives, community members have to be provided possibilities or, more specifically, functionalities which enable them to signalize their proficiencies.

Against this backdrop, in this paper we design and evaluate profile-functionalities that allow VIC members to explicitly signal their skills and capabilities on the basis of existing theories. To design the corresponding functionalities, we follow the design science approach. First, we elaborate on the relevance of the problem at hand and justify our efforts to design the new functionalities. Second, we design the new functionalities on the basis of the signaling theory. In doing so, we intend to answer the following research question:

Which functionalities effectively enable users of a Virtual Ideas Community to signal their skills and competencies? 


\section{Methodical Approach}

We follow the design science approach (Hevner et al., 2004) in our research. The Design Science Research (DSR) approach, originating in the Engineering Sciences, has increased in popularity of late among researchers in the IS domain, as it represents a set of analytical techniques and perspectives for performing research in IS (Eekels \& Roozenburg, 1991; Vaishnavi \& Keuchler, 2004). We first elaborated on the relevance of the problem at hand and justified our efforts to design the new functionalities. Within this first cycle (relevance cycle) we also identified the requirements for our artefact within the application domain. Thereby, we intended to build the foundations for the following design activities. These activities are part of the second cycle (design cycle) within which we design our artefact. Third, we discuss the results of our design efforts as well their consequences to the existing knowledge (rigor cycle). Our methodical approach is depicted in Figure 1.

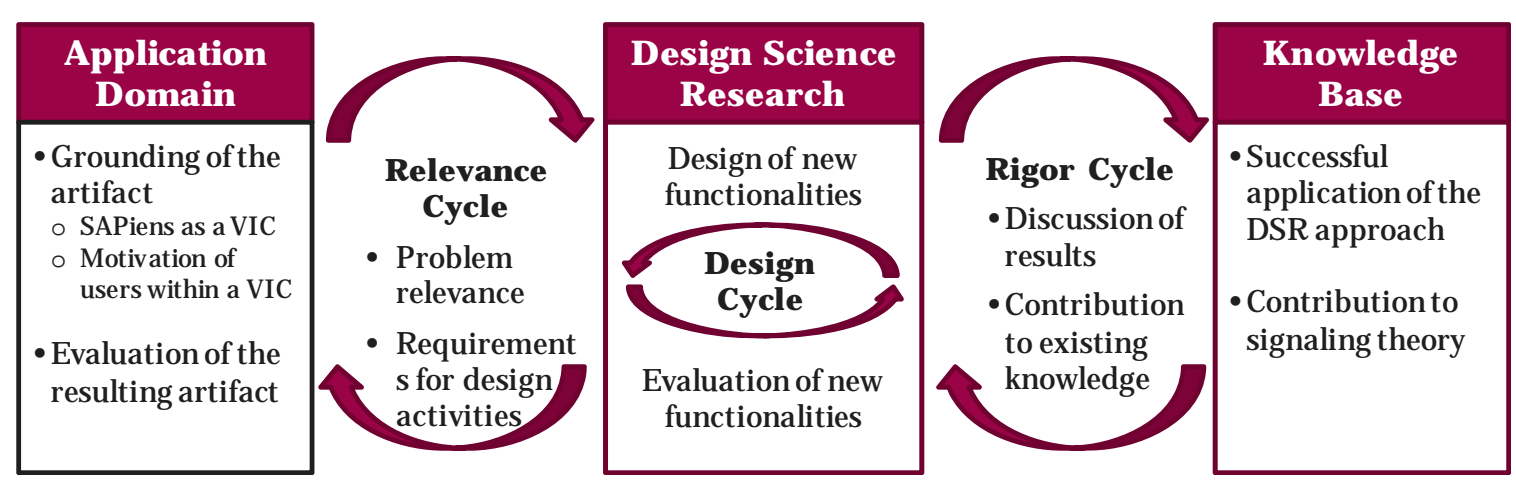

Figure 1: Methodical Approach (adapted from (Hevner et al., 2004))

\section{Users' Signaling Motives within Virtual Ideas Communities}

Before executing the corresponding design efforts, it is necessary to take a closer look at existing knowledge in order to derive requirements for profile functionalities. Therefore, we first specify users' motives that drive users to participate and become active in VICs. We then focus on self-marketing and recognition motives, which we regard as being relevant moving causes for users to express themselves and their inherent abilities in VICs. This will take into account a description of the concept of the signaling theory first developed by Michael Spence (Spence, 1973). 


\subsection{Motives in VICs}

Idea communities such as SAPiens support the integration of customers in the early phases of a company’s innovation process. Here, companies try to acquire plentiful, as well as valuable, innovation ideas from community members. The success of VICs thus strongly depends on the willingness of community members to submit own ideas and contribute to other ideas within the community. Meanwhile, this engagement of submitting ideas and contributing to other members' ideas in VICs strongly depends on the motives of the community members (Ebner et al., 2009; Leimeister et al., 2009). To strengthen the engagement of the community members as well as to get highly qualitative and innovative ideas and contributions, it is therefore crucial for the provider of such platforms to have a detailed understanding of community members' motivation. This understanding is necessary to develop a community concept that fits to the motivation of the community members. A review of studies that focus on virtual communities reveals that motives function as pivotal factors that affect the behaviour of humans regarding their activity in online communities (Hertel et al., 2003b; Shah, 2006; Tedjamulia et al., 2005; Wasko \& Faraj, 2000).

Generally, motives are considered as the moving causes for human behaviour, as they represent the driving forces that adjust an individual's behaviour towards a concrete goal (e.g., Stagner, 1977). Therefore, motives contain an activating component that empowers the organism to act and achieve a cognitive minted goal orientation. The connection of these two components can be seen in a specific action (e.g., posting an idea in a virtual community) which is undertaken to satisfy a certain motive (e.g., gaining peer recognition). Thus, a human is encouraged by his motives to undertake a certain behaviour. Motives are temporally, relatively stable, psychological dispositions of individuals, which are partly inborn and partly acquired in the course of a human's socialization process (Brennecke \& Amick, 1978; Lakhani \& von Hippel, 2003).

In the field of motivational psychology, there are different approaches to classify the various motives. For instance, it is a common method to differentiate humans' motives into intrinsic and extrinsic motives (see e.g., Cotton et al., 1997; Dagenais, 1998; Harter \& Jackson, 1992; Ryan \& Deci, 2000). According to Staw (1976), or Benabou and Tirole (2003), amongst others, intrinsic motivation refers to the pleasure or value associated with the activity itself (e.g., a person plays chess because he/she enjoys effortful thinking). The underlying motives here are stimulated by an inborn feeling, such as hunger or thirst, not by an external or situational 
context (Deci \& Ryan, 1985). Extrinsic motivation, on the other hand, refers to the value an individual places on the ends of an action and the probability of reaching these ends (Staw, 1976). The underlying motives arise directly from external stimuli that are perceived from situational context. These are external rewards, such as money, awards, or recognition (e.g., an individual participates in an ideas competition because of the prize money or because he/she seeks for recognition from peers).

In the scientific field of open innovation, several studies have tried to examine consumers' motivation and the underlying motives for participating in open innovation activities. The focus is especially on intrinsic motives, which encourage individuals to take part in VICs even though the operators do not offer monetary or material rewards. This circumstance applies also to open source projects within which individuals take part without being rewarded monetarily for their effort. Reviewing several studies that examine consumers' motives for participating in open source projects (e.g., Ghosh et al., 2002; Hars \& Ou, 2002b), Bretschneider and Leimeister (2011) outline six motives that can be considered as moving causes for taking part in VICs. Motives such as ‘altruism,' ‘learning’ and ‘fun’ (e.g., joy of programming) have been examined in several studies - most often in the course of open source communities (Ghosh et al., 2002; Shah, 2006). Other studies have outlined the will of VIC users to 'improve certain products' by contributing their ideas (Di Gangi \& Wasko, 2009; West \& Lakhani, 2008).

There has, however, been less focus on the motive of 'self-marketing' - especially within the frame of VICs. We suggest that this motive is highly relevant when considering VICs: Members of a VIC participate in VICs not only to satisfy their creative urge and product-related curiosity (fun-motive), but also for self-marketing reasons. For community members, this motive manifests itself in the possibility of proving their skills, know-how and talent to the operating company. In doing so, the community members are able to recommend themselves as promising potential workforces. Self-marketing thus refers not only to career possibilities derived from active participation in a virtual community, but also to community members' endeavour of gaining recognition by peers and other community members.

However, existing VICs do not provide their members with the possibility of actively highlighting these attributes, even though members have the need to showcase their skills. We suggest that the intention to demonstrate personal capabilities or competencies - either to improve job opportunities or to attain recognition within the community - can be compared with 
the situation of job candidates in the labour market, who try to signalize their skills to potential employers. In either context, there are information asymmetries between two parties: The first party (e.g., employee, community member) is well-informed about, in this case, the personal competencies, whereas the other party (e.g., employer, community provider) is not able to determine the first party's characteristics. Thus, the first party seeks ways to disclose, respectively, signalize the personal abilities. In this paper, we propose signaling to be a viable and under-examined mechanism through which community members are able to reveal their competencies and thereby satisfy the underlying motives, i.e., the self-marketing motive. In the subsequent section we outline the theory behind this mechanism.

\subsection{Signaling Theory}

The basal premise of the signaling theory is that the information distribution between different actors in the market is imperfect (Boulding \& Kirmani, 1993). By using an example from the second-hand car market, Akerlof (1970) describes in his prominent article "market for lemons” that in a situation where buyers cannot ascertain the quality of products (i.e., certain used cars), markets would collapse because of buyers' accruing aversion to buy these products. In this case, the second-hand car market is characterized by asymmetric information distribution, resulting in the fact that customers do not have the same information as vendors. Therefore, customers are not able to determine the 'real' quality of a specific car. Cars with a higher quality and correspondingly higher prices do not get sold because buyers are unsure about the true quality of the used cars. "As a result there tends to be a reduction in the average quality of goods and also in the size of the market”(Akerlof, 1970).

In his formulation of the signaling theory, Spence (1973) shows that in markets characterized by information asymmetry (such as the described second-hand car market), reestablishment of effective exchange could be achieved if 'above-average' quality product sellers could engage in (some costly) effort to signal their quality to the market (Ndofor \& Levitas, 2004). In order to model the signaling mechanism, Spence (1973) utilizes the labour market and the inherent asymmetric information distribution. Here, potential employers (i.e., firms) are insufficiently informed about the quality of job candidates. However, job candidates can utilize their education level as a signal to demonstrate their 'quality' - i.e., their competencies and abilities - to potential employers (Connelly et al., 2011). Such signals are important because they contain and reveal information about unobservable characteristics of a job seeker to the uninformed employer (Ndofor \& Levitas, 2004). According to Spence (1974), signals can be considered 
as "activities or attributes of individuals in a market, which, by design or accident, alter the beliefs of, or convey information to, other individuals in the market” (Spence, 1973). Signals are effective provided that they supply information about the quality of the unobservable characteristics or attributes.

As stated previously, in Michael Spence's exposition, the educational level serves as one possible way to signal an applicant's unobservable qualities. However, there are also other possibilities to signal personal skills. For instance, postgraduate trainings (Sieben, 2007) or advanced vocational trainings (Hämäläinen, 2002) that are provided by universities, municipal consultancy operations or education companies. Successfully completed trainings demonstrate potential to employers the worker quality or other attributes, such as high motivation and abilities. Second, work experience in general or work experience with specific artefacts (Häkkinen, 2006; Rich, 1996) may also function as a signal. For instance, nowadays employers very often demand a specific level of knowledge or an amount of experience with certain software programs. In this connection, specific training courses regarding the required (software) program may also highlight further personal qualities or skills (Blundell et al., 1996; Booth, 1993; Richardson \& Van den Berg, 2002).

Referring to the self-marketing motive outlined in the previous section, we know that VIC users inherit the need to demonstrate their skills and abilities in order to make themselves attractive for the VIC provider or enhance their reputation within the community. In this setting, we virtually have a market interaction, in which community members know their qualities and want to express these, but the operators as well as the community members are not fully informed about these qualities. Hence, in order to be able to satisfy this depicted motive, community members have to be provided possibilities or, more specifically, functionalities which enable them to signalize their proficiencies.

\section{Design of the Signaling Supporting Components}

After having grounded our design efforts in existing theories as well as in existing practical applications, we now describe the resulting functionalities that we implemented on SAPiens. In the previous section, we found that self-marketing is a relevant motive in the context of virtual ideas communities. We constituted that signaling and thus also the self-marketing motive can be enhanced by offering community members a section within their profile where they can document personal abilities. In order to enable community members to signal their skills and competencies, we identified three different aspects: (1) work experience (Häkkinen, 
2006; Rich, 1996), (2) specific training courses (Blundell et al., 1996; Booth, 1993; Richardson \& Van den Berg, 2002) and (3) advanced vocational training (Hämäläinen, 2002; Sieben, 2007). Accordingly, the resulting functionalities have to address these different aspects which enable community members to effectively signalize their skills and competencies according to the topic of the community as well as its skills and competencies in other fields.

In order to ensure that the resulting functions satisfy the users' needs, we constantly evaluated our artefacts. We therefore interviewed community members in order to learn about their needs. Additionally, we interviewed two moderators and two administrators of the SAPiens community in order to find out more about the kind of information that would be interesting to them. Moreover, we used these interviews to explore the technical constraints when implementing the resulting functionalities on SAPiens. Table 1 provides an overview of the different evaluation steps.

Table 1: Evaluation Steps within the Design Cycle

\begin{tabular}{|c|c|c|c|}
\hline Evaluation steps & Step 1 & Step 2 & Step 3 \\
\hline $\begin{array}{l}\text { Methodical } \\
\text { Approach }\end{array}$ & $\begin{array}{l}\text { Semi-structured } \\
\text { Interviews }\end{array}$ & $\begin{array}{l}\text { Semi-structured } \\
\text { Interviews }\end{array}$ & Expert discussions \\
\hline $\begin{array}{l}\text { Subject of inter- } \\
\text { est }\end{array}$ & $\begin{array}{l}\text { Broad insight into the needs } \\
\text { of customers }\end{array}$ & $\begin{array}{l}\text { Insights into the } \\
\text { needs of the } \\
\text { community host }\end{array}$ & Technical constraints \\
\hline Interlocutor & $\begin{array}{l}\text { Community members of } \\
\text { SAPiens }\end{array}$ & $\begin{array}{l}\text { Moderators of } \\
\text { SAPiens }\end{array}$ & $\begin{array}{l}\text { Administrators of } \\
\text { SAPiens }\end{array}$ \\
\hline Results & $\begin{array}{l}\text { Free text boxes in order to } \\
\text { express the full range of } \\
\text { competencies } \\
\text { Drop-down-menu sufficient } \\
\text { to express SAP-related ex- } \\
\text { periences }\end{array}$ & $\begin{array}{l}\text { Special interest in } \\
\text { SAP related } \\
\text { competencies }\end{array}$ & Design requirements \\
\hline
\end{tabular}

As a result of these interviews, we launched three sections within the user's profile: "about me," "SAP domains that I am an expert in" and "level of expertise related to SAP.” In order 
to give community members the possibility to signalize their work experience in regard to the usage of the several SAP-products, we designed a section dealing with the "level of expertise related to SAP.” This section comprises a drop-down register that enables the users to select among three different levels of SAP-experiences. By implementing this section, we intended the users to signal their expertise to other community members, thus satisfying their need for recognition.

To realize the signaling of specific training courses, a section called "SAP domains that I am an expert in" was designed as a free text box. In this section the users are expected to provide information about the SAP-products and -areas that they have addressed in the course of past training courses. One example of such courses is the successful attendance of a SAP TERP 10 course. In this field the community members have the possibility to list up to ten different topics that are displayed publicly in the user's profile. By providing this section to the community members, users are able to satisfy their self-marketing motive by showing their SAPrelated skills and competencies to the host of the community. The users are thereby able to provide the host with the possibility of contacting interesting community members selectively for the purpose of future recruiting measures. Moreover, users are able to show their SAPrelated skills to the community, thus satisfying their need for recognition among peers and allowing them to contact a suitable user in case they need help in elaborating on a submitted idea.

To give the community members the opportunity to signal postgraduate trainings or advanced vocational training not directly related to the topic of the community, we designed the "about me” section. In this section members are able to insert general information about themselves as well as their skills and competencies that are not directly related to the field of SAP. Here, users of our community have the opportunity to write a random number of letters into a free text field. The information provided is then displayed publicly within the user's profile. We implemented this section in order to give the community members the possibility of signaling their full range of competencies to the host of the community - in this case SAP. In this way, we intend to satisfy the users self-marketing motive. Figure 2 illustrates the resulting functionalities as well as their implementation on SAPiens. Please note that the screenshot was made anonymous. 


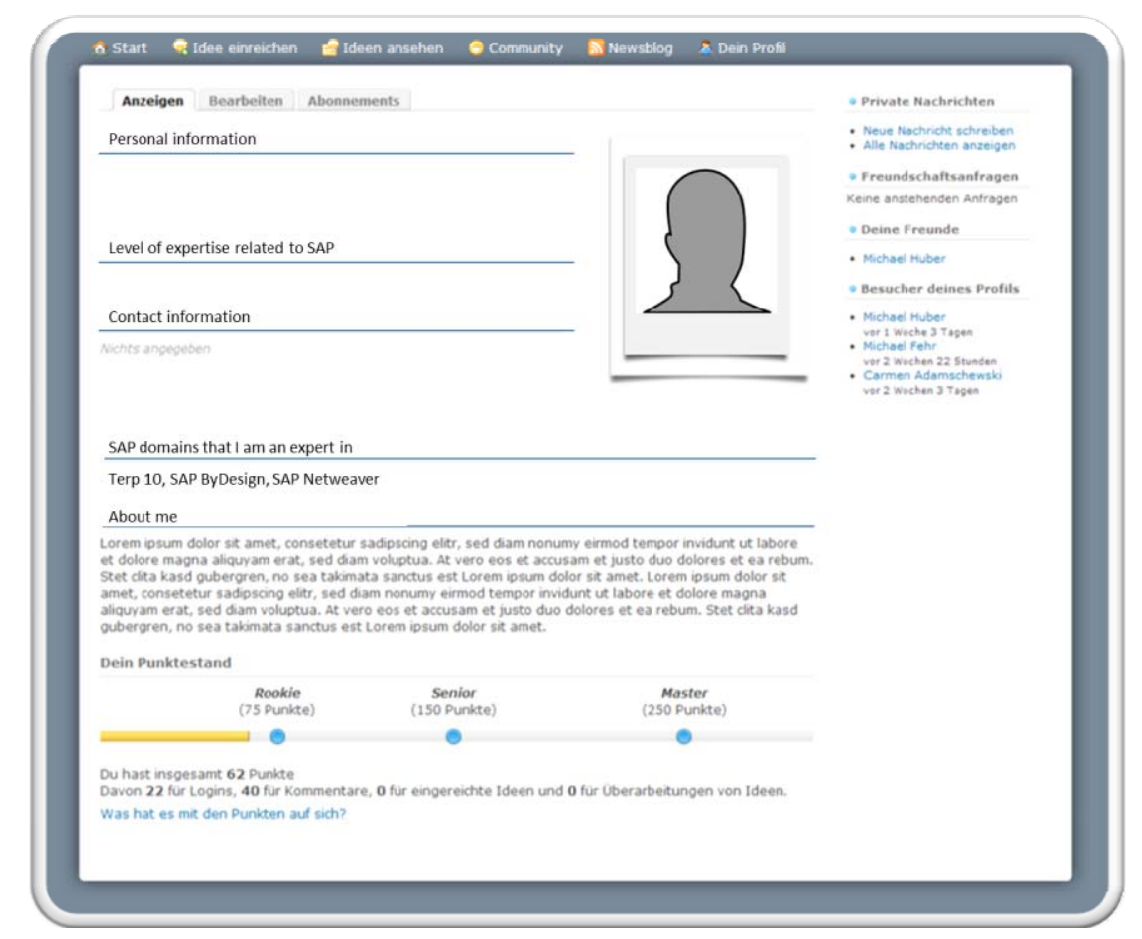

Figure 2: Profile Section within SAPiens

\section{Discussion}

The results of this research in progress provide different implications for VIC providers in practice: First, we demonstrate what kind of functionalities can be designed on the basis of the signaling theory in order to address the self-marketing motive of community users. Based on insights from signaling theory, we have been able to develop three different functionalities that can be set up within the profiling section. The study then reveals if these functionalities are appropriate for enabling the self-marketing motivated users to signalize their skills and abilities. Based on the upcoming results, VIC providers will be offered suggestions if, and if so, how to implement such functionalities in their communities.

Meanwhile, the theoretical contribution of this ongoing research will be twofold. In the first place, this research will contribute to the design process of VICs. It is acknowledged that the continuous development and improvement of online communities in general is necessary for those to remain interesting and appealing to users. Our work will demonstrate if the DSR approach (in our specific case) is useful regarding the design of specific functionalities that address customers' motives adequately. Our artefact is just one example that outlines how it is possible to design new applications for VICs purposefully based on the DSR approach. 
In the second place, we hope to contribute to the signaling theory, which hitherto has not been considered in the course of virtual community research. Various studies within the field of information economics have empirically shown that the signaling mechanism works because thereby information asymmetries are eliminated (Connelly et al., 2011). Also within marketing - where various marketing-mix measures are utilized to signal the unobservable quality of a product - it has been shown that effective signaling leads to a higher quality perception (Kirmani \& Rao, 2000). The underlying research now takes into account the signaling mechanism in the field of IS: We build upon the idea behind the signaling theory - i.e., we use the signaling mechanism in order to eliminate information asymmetries between community members amongst themselves, as well as between community members and the communityoperator. Our findings will show that the functionalities we developed are used by community members who inherit the self-marketing motive. We thus hope to analyse the relevance and the significance of the signaling theory within the setting of VICs.

\subsection{Next Steps and Future Research}

Nevertheless, as this is a research in progress work, the final evaluation of the resulting functionalities has not been finished. Hence, we are not able to predict whether the expected implications can be fully realized. As a consequence, our future research will aim at completing the evaluation of the proposed functionalities. In order to determine whether the new functionalities are capable of fulfilling users' needs, we intend to evaluate them within the application domain. It is thus important to identify appropriate methods that allow for the evaluation of an artefact in regard to the proposed goal (Hevner, 2007). The objective of this paper was to design profiling functionalities that would be able to satisfy users' motives of signalizing their skills and competencies. Given this goal, we will evaluate the implemented functionalities based on their ability to fulfil the corresponding motives of the community members. We will therefore implement the functionalities on SAPiens and promote them within the community. Thereafter, we will evaluate the functionalities based on the user's perception. In doing so, we intend to come up with an artefact that will enable users of a VIC to directly signalize their proficiencies in order to satisfy their self-marketing needs. 


\section{References}

Akerlof, G. A. (1970) The Market for "Lemons": Quality Uncertainty and the Market Mechanism. The Quarterly Journal of Economics, 84, 488-500.

Benabou, R. and Tirole, J. (2003) Intrinsic and Extrinsic Motivation. The Review of Economic Studies, 70, 489-520.

Blundell, R., Dearden, L. and Meghir, C. (1996) The Determinants and Effects of Work Related Training in Britain. London: The Institute for Fiscal Studies.

Booth, A. L. (1993) Private Sector Training and Graduate Earnings. The Review of Economics and Statistics, 75.

Boulding, W. and Kirmani, A. (1993) A Consumer-Side Experimental Examination of Signalling Theory. The Journal of Consumer Research, 20, 111-123.

Brennecke, J. H. and Amick, R. G. (1978) Psychology and human experience. Encino, Calif.: Glencoe Pub. Co.

Bretschneider, U. (2012) Die Ideen-Community zur Integration von Kunden in den Innovationsprozess: Empirische Analysen und Implikationen. Wiesbaden: Springer Gabler.

Bretschneider, U. and Leimeister, J. M. (2011) Getting customers' motives: Lean on motivation theory for designing virtual ideas communities IFIP Working Group 8.6.

Connelly, B. L., Certo, S. T., Ireland, R. D. and Reutzel, C. R. (2011) Signaling Theory: A Review and Assessment. Journal of Management, 37, 39-67.

Cotton, L., Bynum, D. R. and Madhere, S. (1997) Socialization forces and the stability of work values from late adolescence to early adulthood. Psychological Reports, 80, 115-124.

Dagenais, F. (1998) Super's work values inventory scales as intrinsic or extrinsic constructs. Psychological Reports, 83, 197-198.

Deci, E. L. and Ryan, R. M. (1985) Intrinsic Motivation and Self-Determination in Human Behavior. Heidelberg: Springer.

Di Gangi, P. M. and Wasko, M. (2009) Steal my idea! Organizational adoption of user innovations from a user innovation community: A case study of Dell IdeaStorm. Decision Support Systems, 48, 303-312.

Ebner, W., Leimeister, J. M. and Krcmar, H. (2009) Community Engineering for Innovations: the Ideas Competition as a Method to Nurture a Virtual Community for Innovations. R\&D Management, 39, 342-356.

Eekels, J. and Roozenburg, N. (1991) A Methodological Comparison of the Structures of Scientific Research and Engineeringdesign: Their Similarities and Differences. Design Studies, 12, 197-203.

Gerybadze, A. (2004) Technologie- und Innovationsmanagement : Strategie, Organisation und Implementierung München, Germany: Vahlen Verlag.

Ghosh, R. A., Glott, R., Kreiger, B. and Robles, G. (2002) The Free/Libre and Open Source Software Developers Survey and Study- FLOSS. University of Maastricht, International Institute of Infonomics.

Häkkinen, I. (2006) Working while enrolled in a university: does it pay? Labour Economics, 13, 167189.

Hämäläinen, K. (2002) The effectiveness of labour market training in different era of unemployment. In: Ilmakunnas, S. and Koskela, E., eds. Towards Higher Employment: The Role of Labour Market Institutions. Helsinki: Government Institute for Economic Research.

Hars, A. and Ou, S. (2002a) Working for Free? Motivations for Participating in Open-Source Projects. International Journal of Electronic Commerce, 6, 25-39.

Hars, A. and Ou, S. (2002b) Working for free? Motivations for participating in open-source projects. International Journal of Electronic Commerce, 6, 25-39.

Harter, S. and Jackson, B. K. (1992) Trait vs. nontrait conceptualizations of intrinsic/extrinsic motivational orientation. Motivation and Emotion, 16, 209-230. 
Hertel, G., Niedner, S. and Herrmann, S. (2003a) Motivation of Software Developers in Open Source Projects: An Internet-Based Survey of Contributors to the Linux Kernel. Research Policy, 32, 11591177.

Hertel, G., Niedner, S. and Herrmann, S. (2003b) Motivation of software developers in open source projects: An internet-based survey of contributors to the Linux kernel. Research Policy, 32, 11591177.

Hevner, A. (2007) A Three Cycle View of Design Science Research. Scandinavian Journal of Information Systems, 19, 87-92.

Hevner, A. R., March, S. T., Park, J. and Ram, S. (2004) Design Science in Information Systems Research. MIS Quarterly, 28, 75-105.

Kirmani, A. and Rao, R. A. (2000) No Pain, No Gain: A Critical Review of the Literature on Signling Unobservable Product Quality. Journal of Marketing, 64, 66-79.

Lakhani, K. R. and von Hippel, E. (2003) How open source software works: "free" user-to-user assistance. Research Policy, 32, 923-943.

Lakhani, K. R. and Wolf, B. (2005) Why Hackers Do What They Do. Understanding Motivation and Effort in Free/Open Source Software Projects. In: Feller, J., Fitzgerald, B., Hissam, S. and Lakhani, K. R., eds. Perspectives on Free and Open Source Software. Cambridge, MA: The MIT Press.

Leimeister, J. M., Huber, M., Bretschneider, U. and Krcmar, H. (2009) Leveraging Crowdsourcing: Activation-Supporting Components for IT-Based Ideas Competitions. Journal of Management Information Systems, 26, 197-224.

Ndofor, H. A. and Levitas, E. (2004) Signaling the Strategic Value of Knowledge. Journal of Management, 30, 685-702.

Rich, L. M. (1996) The long-run impact of teenage work experience: A Reexamination The Review of Black Political Economy, 25, 11-36.

Richardson, K. and Van den Berg, G. J. (2002) The Effect of Vocational Employment Training on the Individual Transition Rate from Unemployment to Work. IFAU - Institute for Labour Market Policy Evaluation, Working Paper, 2002:8

Ryan, R. M. and Deci, E. L. (2000) Self-determination theory and the facilitation of intrinsic motivation, social development, and well-being. American Psychologist, 55, 68-78.

Shah, S. K. (2006) Motivation, Governance, and the Viability of Hybrid Forms in Open Source Software Development. Management Science, 52, 1000-1014.

Sieben, I. (2007) Does training trigger turnover - or not? : The impact of formal training on graduates' job search behaviour. Work, Employment \& Society, 21, 397-416.

Spence, M. (1973) Job market Signalling. The Quarterly Journal of Economics, 87, 355-374.

Stagner, R. (1977) Homeostasis, discrepancy, dissonance: A theory of motives and motivation Motivation and Emotion, 1, 103-138.

Staw, B. M. (1976) Intrinsic and extrinsic motivation. Morristown, N.J.: General learning Press.

Tedjamulia, S. J. J., Dean, D. R., Olsen, D. L. and Albrecht, C. C. (2005) Motivating Content Contributions to Online Communities: Toward a More Comprehensive Theory Proceedings of the 38th Hawaii International Conference on System Sciences.

Vaishnavi, V. and Keuchler, W. (2004) Design Reserach in Information Systems. Association for Information Systems.

von Hippel, E. (2005) Democratizing Innovation. . Cambridge, UK: MIT Press.

Wasko, M. M. and Faraj, S. (2000) 'It is what one does': Why people participate and help others in electronic communities of practice. Journal of Strategic Information Systems, 9, 155-173.

West, J. and Lakhani, K. R. (2008) Getting Clear About Communities in Open Innovation. Industry and Innovation, 15, 223-231. 